
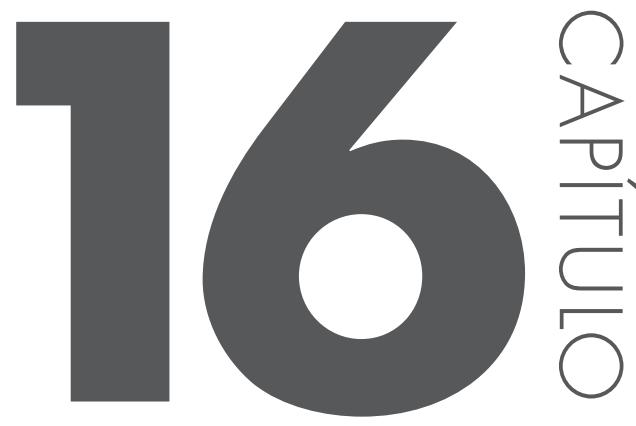

\title{
CONTROLE
}

\section{NEUROENDÓCRINO DA SACIEDADE}

Jacqueline Isaura Alvarez-Leite Fabíola Lacerda Pires Soares

Lílian Gonçalves Teixeira

\subsection{INTRODUC̣ÃO}

O peso corporal é regulado por um complexo sistema que coordena a ingestão alimentar e o gasto energético. O cérebro interpreta e integra os sinais neuronais e hormonais para promover uma resposta reguladora coordenada da homeostase energética. Esse sistema é centrado no hipotálamo e no tronco cerebral, os quais possuem conexões neuronais recíprocas. Especificamente dois grupos de neurônios do núcleo arqueado do hipotálamo parecem ser cruciais: neurônios orexígenos (ligados ao estímulo do apetite) que expressam o neuropeptídeo Y (NPY) e a proteína relacionada à agouti (AgRP), e neurônios anorexígenos (rela- 
cionados à saciedade) que expressam pró-opiomelanocortina (POMC) e transcrito regulado por anfetamina e cocaina (CART).

Os sinais importantes para esse sistema regulatório da homeostase energética incluem, primeiramente, os sinais a curto prazo que indicam a ingestão de uma refeição, uma função coordenada principalmente pelo "eixo intestino-cérebro". Tal eixo existe para transmitir informações vindas do trato gastrointestinal para o hipotálamo e o tronco cerebral, através dos hormônios intestinais e do nervo vago. Em segundo lugar, a regulação dos estoques de energia a longo prazo é feita principalmente pela insulina e leptina que sinalizam para o cérebro o balanço energético. Em terceiro lugar, os ritmos circadianos também influenciam o apetite. Assim, a produção de certos hormônios correlaciona entre si de acordo com o ciclo circadiano. Este capítulo se concentrará principalmente no estudo do eixo intestino-cérebro da regulação da ingestão alimentar e estoques de energia corporais.

O hipotálamo desempenha importante papel no controle do apetite. Baseado nos primeiros estudos dessa área, acreditava-se que a área hipotalâmica lateral agiria como um "centro da fome" e o núcleo hipotalâmico ventromedial como o "centro da saciedade"; entretanto, já foi demonstrado que vários outros núcleos hipotalâmicos e circuitos neuronais estão intrinsecamente envolvidos na regulação do apetite, interagindo com o tronco cerebral e centros corticais superiores.

Os sinais periféricos possuem papel fundamental na transmissão de informações via fibras aferentes vagais para o tronco cerebral ou diretamente para o hipotálamo. Tais sinais transmitem informações como distensão gástrica, níveis de hormônios e ácidos graxos. Dentro do tronco cerebral, é mostrado que os neurônios vagais aferentes expressam uma variedade de receptores, incluindo aqueles para colecistoquinina (CCK), leptina, peptídeo semelhante ao glucagon 1 (GLP-1) e 2 (GLP-2), além dos receptores para grelina. A expressão de receptores de leptina e insulina no tronco cerebral é similar à expressão vista no hipotálamo. No tronco cerebral também existem outras populações neuronais relacionadas à regulação do apetite, tais como o POMC.

$\mathrm{O}$ trato gastrointestinal, juntamente com o pâncreas, forma o maior orgão endócrino do corpo. 30 genes de hormônios intestinais são expressos e cerca de 100 peptídeos bioativos são produzidos no trato gastrointestinal. A antecipação de uma refeição, bem como alimento no estômago e intestino delgado, promovem a secreção de muitos desses hormônios intestinais, por via de estímulos mecânicos e químicos. Esses sinais estão envolvidos tanto com o início como com o término da ingestão alimentar. Os principais sítios do organismo onde tais hormônios exercem seus efeitos podem ser observados na Figura 16.1. 


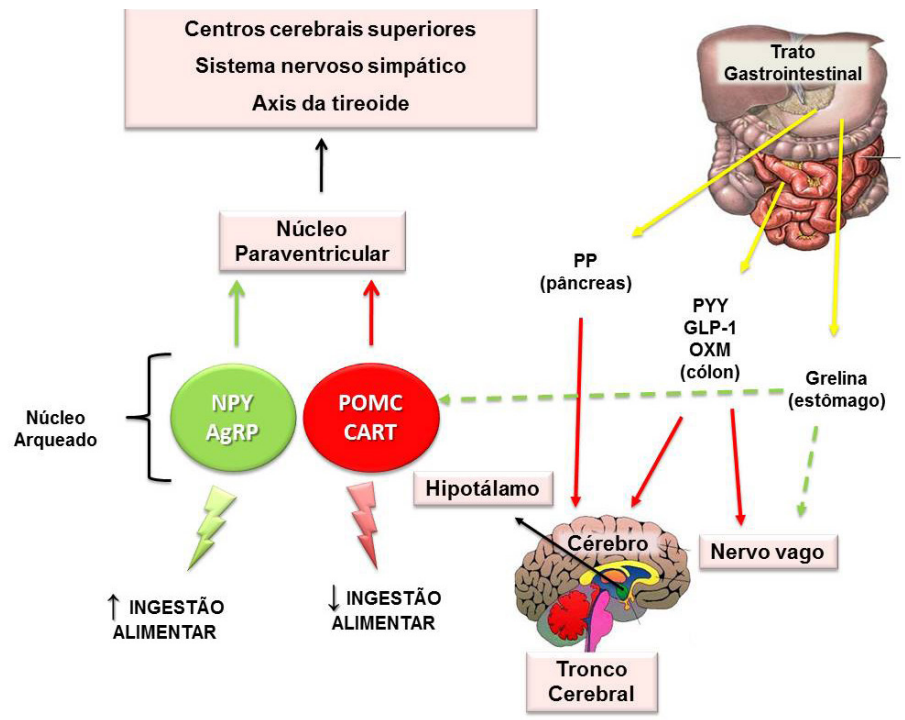

Figura 16.1 - Principais sítios de ação dos hormônios intestinais influenciando a ingestão alimentar:hipotálamo, tronco cerebral e nervo vago. NPY - neuropeptídeo Y, AgRP - proteína relacionada à agouti, POMC - pró-ópiomelanocortina, CART - transcrito regulado por anfetamina e cocaína.

A regulação do consumo de energia é mediada por diversos fatores. A integração central dos sinais periféricos, incluindo aqueles mediados por mecanorreceptores e quimiorreceptores, sinalizam densidade de energia do alimento contido no trato gastrointestinal, enquanto os sensores hipotalâmicos monitoram as flutuações na glicemia. Dois hormônios identificados como cruciais na regulação a longo prazo do balanço de energia são a insulina e leptina. Ambas são liberadas proporcionalmente à gordura corporal, transportados para o cérebro, onde irão modular a expressão de neuropeptídeos hipotalâmicos que regulam o comportamento alimentar e o peso corporal. Embora a liberação de insulina esteja diretamente relacionada ao consumo alimentar, a leptina não se correlaciona com a ingestão de alimentos, refletindo principalmente a massa de gordura corporal. 


\subsection{INTEGRAC̣ÃO HIPOTALÂMICA}

O hipotálamo recebe inervação de diversas áreas, especialmente do núcleo do trato solitário e na área postrema no tronco encefálico. Estas áreas liberam vários sinais neurais e hormonais vindos do trato gastrointestinal. O principal hormônio associado ao controle da saciedade é colecistoquinina (CCK), liberada pelo duodeno em resposta dos lipídios ou proteínas no lúmen intestinal. Ela atua por meio de receptores sensoriais no duodeno, enviando sinais ao cérebro sobre o conteúdo nutricional no intestino. O núcleo do trato solitário também libera informação sobre o paladar dos alimentos para os centros do hipotálamo e outros centros. Sinais sobre olfato, visão, memória de alimentos e do contexto social em que ele é ingerido também estão integrados e podem influenciar o consumo de energia pela modulação eferente do hipotálamo. A integração destes sinais resulta na ativação da expressão gênica de mediadores envolvidos na regulação da saciedade e desenvolvimento da obesidade. Estes genes controlam a disponibilidade da termogênese (proteínas desacopladoras), a síntese hormonal (grelina, leptina e colecistocinina e adiponectina) e neurotransmissores (neuropeptídeo Y).

As contribuições relativas desses mediadores para a regulação da ingestão calórica, gasto energético, peso corporal e massa gorda não são completamente compreendidas. Descobertas importantes, no entanto, como a função secretora do tecido adiposo, forneceram novos fatores para a hoemostase calórica. O tecido adiposo participa desta complexa rede que regula a homeostase energética, o metabolismo da glicose e lipídios, a homeostase vascular e resposta imune, e mesmo a reprodução. Entre os hormônios identificados que são produzidos pelo tecido adiposo estão a leptina, as citocinas (TNF, interleucina-6), o angiotensinogênio, o inibidor do ativador do plasminogênio-1 (PAI1), adiponectina, resistina e outros. A secreção de quase todos esses hormônios e citocinas é desregulada como consequência tanto do excesso quanto da deficiência na massa de tecido adiposo, o que sugere que eles estão envolvidos na fisiopatologia da obesidade e caquexia.

Assim, de certo modo, o sistema neuroendócrino envolvido no controle da ingestão alimentar e composição corporal compreende atuação de vários órgãos incluindo o trato gastrointestinal (o pâncreas, o sistema nervoso central, as adrenais e o tecido adiposo). 


\subsection{HORMÔNIOS INTESTINAIS: VISÃO GERAL}

Os hormônios intestinais envolvidos no controle do apetite podem ser orexígenos ou anorexígenos. Fisiologicamente, a grelina é o único hormônio verdadeiramente orexígeno encontrado até o momento, enquanto vários hormônios anorexígenos são descobertos. Esses hormônios parecem agir como iniciadores ou finalizadores de uma refeição, dessa forma tendo influência sobre a ingestão energética a curto-prazo. Os hormônios intestinais circulantes influenciam a atividade neuronal no sistema nervoso central ou diretamente pela penetração na barreira hematoencefálica, agindo dessa maneira no hipotálamo e no tronco cerebral, ou via receptores no nervo vago aferente.

Nesse grupo de hormônios intestinais estão as incretinas, que aumentam a liberação de insulina em resposta à ingestão oral de glicose, mas não após a administração intravenosa. As incretinas são secretadas pelo trato gastrointestinal durante a ingestão alimentar e ligam-se a receptores específicos acoplados à proteína G, os quais podem ser encontrados no pâncreas, estômago, músculo esquelético, coração, pulmão e cérebro. Os principais locais de síntese dos hormônios intestinais e suas ações podem ser observados na Figura 16.2.

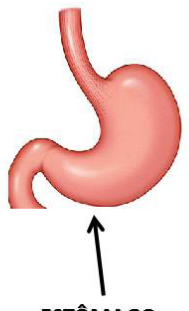

ESTÔMAGO

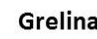

Fome Liberação $\mathrm{GH}$

Gastrina Secreção ácida
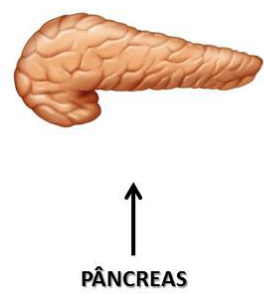

Insulina e Glucagon Homeostase da Glicose

PP

Saciação

Motilidade Gástrica

Amilina

Homeostase de Glicose

Motilidade Gástrica

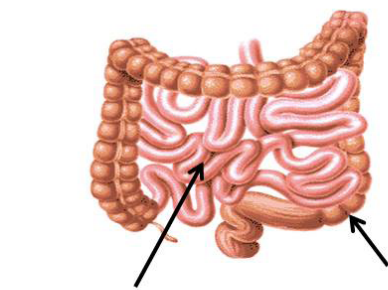

INTESTINO DELGADO

CCK

Contração da vesícula biliar Motilidade Gastrointestinal Secreção exócrina pâncreas

Secretina

Secreção exócrina pâncrea

GIP

Atividade de incretina

Motilina

Motilidade Gastrointestinal
COLON

GLP-1

Atividade de incretina

Saciação

GLP-2

Motilidade Gástrica

OXM

Saciação

Secreção gástrica

PYY (3-36)

Saciação

Figura 16.2 - Principais locais e produção e ação dos hormônios intestinais. 


\subsection{HORMÔNIOS LIGADOS À REGULAC̣ÃO DA INGESTAOO ALIMENTAR}

\subsubsection{HORMÔNIO OREXÍGENOS}

\subsubsection{GRELINA}

A grelina é um peptídeo acilado com ação orexígena, composto de 28 aminoácidos, sendo formado pela clivagem do seu precursor maior, o pré-pró-glucagon. É secretada principalmente pelas células tipo X/A da glândula oxíntica gástrica, mas é também expressa em níveis menores no intestino delgado, hipotálamo e placenta. A grelina é um ligante endógeno para o receptor secretagogo do hormônio de crescimento, localizado no núcleo arqueado hipotalâmico, especialmente nos neurônios que reconhecem o NPY, e somente na forma ligada é capaz de atravessar a barreira hematoencefálica. A desacil-grelina é a principal forma no plasma e pode ser acilada a acilgrelina através da enzima grelina aciltransferase-O (GOAT) no estômago. Os níveis circulantes de grelina aumentam quase duas vezes antes de uma refeição e rapidamente diminuem após essa, sendo tal diminuição proporcional ao aporte calórico da refeição. A administração periférica ou diretamente no sistema nervoso central de grelina aumenta a ingestão alimentar e o peso corporal com diminuição da oxidação de lipídeos. A acilgrelina também estimula a adiposidade de forma independente da sua ação hiperfágica. Os níveis plasmáticos de grelina são altos em pacientes com anorexia nervosa e em pacientes com dieta para perda de peso. Nos obesos, a regulação negativa exercida pelo alimento sobre a grelina não existe ou é apenas modesta.

Além dos efeitos orexígenos da grelina, evidências demonstraram seu papel no controle da secreção da prolactina e do hormônio corticotrófico, no metabolismo lipídico e glicídico, na motilidade gástrica e secreção ácida, no funcionamento do coração, no sono e na reprodução. Estudos in vivo e in vitro mostraram ainda que a grelina apresenta efeitos antiproliferativos pela indução da apoptose.

A ação da grelina é mediada pelo aumento das vias NPY/AgRP e pela inibição dos neurônios POMC. O nervo vago parece ser um importante mediador da ação da grelina. 


\subsubsection{NEUROPEPTÍDEO Y (NPY)}

O neuropeptídeo Y (NPY) é o mais poderoso potenciador do apetite. Sua expressão é predominante no núcleo arqueado do hipotálamo, de onde os neurônios NPY projetam para neurônios de segunda ordem, desencadeando vias anabólicas. Até o momento, seis receptores (Y1, Y2, Y3, Y4, Y5 e Y6) já foram isolados, dois dos quais (Y1 e Y 5) parecem mediar os efeitos anabólicos do NPY. Mais de 90\% dos neurônios NPY coexpressam a proteína relacionada à agouti (AgRP). Baixos niveis de leptina, hipoglicemia, hipoinsulinemia e condições negativas de balanço energético aumentam a expressão de RNA mensageiro do NPY no núcleo arqueado do hipotálamo. Sua administração central inibe a termogênese, aumenta a ingestão alimentar e promove a adipogênese em ratos.

\subsection{3 PROTEÍNA RELACIONADA À AGOUTI (AGRP)}

A proteína relacionada à agouti $(\mathrm{AgRP})$ é outra potente proteína orexígena. Sua liberação pelo núcleo arqueado hipotalâmico é inibida pela infusão de leptina, enquanto sua expressão é regulada positivamente em camundongos deficientes em leptina $(o b / o b)$. A AgRP influencia a ingestão alimentar principalmente por via do antagonismo competitivo dos receptores centrais de melanocortina. Aparentemente, qualquer prejuizo no balanço energético provoca a secreção de AgRP. Em contraste com o NPY, a AgRP apresenta uma ação prolongada, tendo um potencial terapêutico nas doenças que se relacionam com anorexia e emagrecimento. Em altos níveis de AgRP, por outro lado, é associado à obesidade.

\subsubsection{HORMÔNIOS ANOREXÍGENOS}

\subsubsection{AMILINA}

A amilina, um peptídeo de 37 aminoácidos, é armazenada e liberada juntamente com a insulina em resposta à ingestão energética. A ação anorexígena da amilina parece estar associada com os sistemas serotonina-histamina e dopaminérgico no cérebro, bem como com a inibição da liberação de NPY. Além disso, a amilina inibe o esvaziamento gástrico e a secreção de glucagon. 


\subsubsection{POLIPETÍDEO PANCREÁTICO (PP)}

O polipeptídeo pancreático (PP) é um peptídeo de 36 aminoácidos, que apresenta baixa conservação de sequência entre espécies. É secretado principalmente pelas ilhotas de Langerhans e em menor quantidade pelo cólon e reto. Acredita-se que o PP reduz a ingestão alimentar diretamente através do receptor Y4 no hipotálamo e tronco cerebral. PP age também via nervo vago, já que a vagotomia inibe os efeitos anorexígenos do PP.

Os níveis circulantes de PP aumentam após uma refeição de modo dependente do aporte calórico e continuam elevados por bastante tempo após o término da refeição, sugerindo que esse peptídeo pode exercer seu principal efeito na alimentação pela indução de saciedade. Outros hormônios, como gastrina, CCK e secretina também estimulam a liberação de PP, enquanto a somatostatina inibe.

\subsubsection{COLECISTOQUININA (CCK)}

A colecistoquinina foi o primeiro hormônio intestinal identificado como modulador da ingestão alimentar. A CCK é derivada da modificação pós-transducional do gene da pró-colecistoquinina, que produz diversos peptídeos com diferentes números de aminoácidos, indicados pelo sufixo numeral: CCK8, CCK22, CCK33 e CCK58. A forma predominante no plasma humano é a CCK33. A CCK é secretada no período pós-prandial pelas células do duodeno e íleo com uma meia vida circulatória de apenas alguns minutos. Seus níveis aumentam rapidamente com um pico de 15 minutos após uma refeição. Os efeitos da CCK no trato gastrointestinal inclui a estimulação da contração da vesícula biliar, secreção de enzimas pancreáticas e inibição do esvaziamento gástrico.

Existem dois subtipos de receptores para CCK, o CCK1 e o CCK2, ambos amplamente distribuídos no cérebro, especialmente no hipotálamo e no tronco cerebral. Sua ação anorexígena parece ser mediada principalmente por meio do receptor CCK1 nos aferentes vagais.

\subsubsection{PEPTÍDEO TIROSINA TIROSINA (PYY)}

O peptídeo tirosina tirosina (PYY) tem 36 aminoácidos, membro da família PP, que também inclui o NPY e o PP. Essa família de peptídeos age por via de receptores acoplados à proteína $\mathrm{G}$, sendo eles o Y1, Y2, Y3, Y4, Y5 e Y6. Duas formas circulantes de PYY são liberadas pelas células L do intestino distal: PYY (1-36) e PYY (3-36). O PYY (3-36) é a principal forma circulante produzida pela clivagem do PYY (1-36) pela enzima dipeptidil peptidase IV (DPP-IV). O PYY (3- 
36) se liga com alta afinidade ao receptor Y2 hipotalâmico (e com menor afinidade nos demais recptores) reduzindo a ingestão alimentar. A concentração de PYY circulante é baixa no jejum e aumenta rapidamente após uma refeição, sendo seu pico 1-2 horas após esta e continuando elevada por horas. Esse perfil de elevação de longa duração sugere que seu efeito seja importante na saciedade. A ingestão de gorduras resulta em maior liberação de PYY comparado com a ingestão de carboidratos ou proteínas.

\subsubsection{PEPTÍDEO SEMELHANTE AO GLUCAGON 1 (GLP-1) E 2 (GLP-2)}

O peptídeo semelhante ao glucagon 1 (GLP-1) é um peptídeo composto por 30 aminoácidos que, juntamente com o peptídeo semelhante ao glucagon 2 (GLP2) e a OXM são derivados do pró-glucagon. O GLP-1 é coexpresso com o PYY pelas células L do intestino e possui um potente efeito de incretina, por estimular a secreção de insulina em um mecanismo dependente de glicose. O GLP-1 é completamente conservado entre todas as espécies dos mamíferos, o que indica sua importância fisiológica. O GLP-1 é expresso principalmente no cérebro, trato gastrointestinal e pâncreas, e sua forma circulante tem meia vida curta, de aproximadamente cinco minutos, em virtude de remoção renal e inativação pela enzima plasmática DPP-IV.

Além de agir como incretina, GLP-1 atua como peptídeo anorexígeno, mediante a ligação com o receptor GLP-1R, que estimula a atividade de adenilato ciclase e AMP cíclico (AMPc). Os níveis circulantes desse peptídeo estão elevados após uma refeição e baixos em estado de jejum. Além de seu efeito na liberação de insulina, GLP-1, exerce efeitos tróficos nas células $\beta$ pancreáticas.

Assim como o GLP-1, o GLP-2 é secretado pelas células enteroendócrinas de forma dependente de nutrientes. Apesar de não apresentar efeitos na ingestão alimentar, exerce efeitos tróficos no intestino e estimula a proliferação das células das criptas intestinais.

\subsubsection{OXINTOMODULINA (OXM)}

A oxintomodulina (OXM) é mais um produto do gene do pró-glucagon. É um peptídeo de trinta e sete aminoácidos e possui vinte e nove aminoácidos da sequência do glucagon. A OXM é secretada pelas células L do intestino em resposta à ingestão alimentar e proporcional ao aporte calórico ingerido. Assim como o GLP-1, a OXM é inativada pela DPP-IV.

Os mecanismos anorexígenos da OXM ainda não estão totalmente esclarecidos. OXM tem a mesma potência na inibição da ingestão alimentar que o GLP-1. 
Seu efeito anorexígeno é dependente do receptor de GLP-1 (GLP-1R), uma vez que pode ser bloqueado por antagonistas deste receptor e abolido em animais que não expressam GLP-1R. Apesar dos efeitos anorexígenos semelhantes, porém, OXM tem afinidade 50 vezes menor pelo GLP-1R comparado ao próprio GLP-1. Alternativamente, podem existir outros receptores de OXM ainda não identificados pelos quais ele exerce suas ações, visto que efeitos cardiovasculares da OXM são preservados em animais que não expressam o GLP-1R. Além disso, parte do efeito da diminuição da ingestão alimentar pode ser causada por uma redução da grelina plasmática, já que a infusão de OXM pós-prandial leva à diminuição de $44 \%$ da grelina circulante em humanos. Os efeitos de incretina por sua vez, aparecem após a administração de glicose e são dependentes de GLP-1R, sugerindo que sua ação na regulação do metabolismo de glicose ocorre via GLP-1R.

\subsubsection{PEPTÍDEO INSULINOTRÓPICO DEPENDENTE DE GLICOSE (GIP)}

Assim como o GLP-1, o peptídeo insulinotrópico dependente de glicose (GIP) também é uma incretina, sendo que os dois peptídeos dividem grande parte da sequência de aminoácidos e são degradados pela enzima DPP-IV. Embora ambos aumentem a secreção de insulina, apenas o GLP-1 suprime a secreção de glucagon. O GIP é um peptídeo de 42 aminoácidos, secretado pelos linfócitos intraepiteliais do duodeno proximal e regulado predominantemente pelo consumo de gorduras. O GIP encontra-se reduzido durante o jejum e aumenta após a ingestão alimentar. O receptor para o GIP é amplamente distribuído no organismo, sendo encontrado no cérebro, duodeno, rim, fígado, pulmão, pâncreas e estômago. A sinalização do receptor é mediada por uma adenilato ciclase acoplada à proteína $\mathrm{G}$, resultando no aumento de AMPc e ativação da proteína cinase A e, consequentemente, no aumento da secreção de insulina.

O mecanismo resumido da ação das principais incretinas pode ser visto na Figura 16.3. 


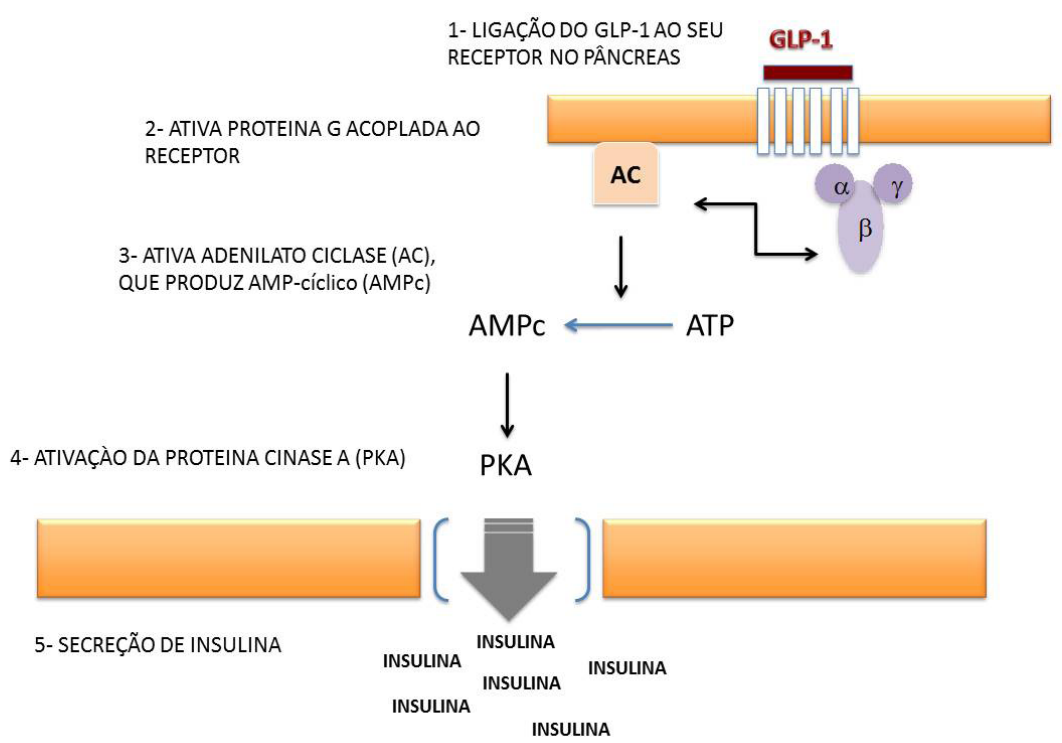

Figura 16.3 - Mecanismo de ação das principais incretinas. A ligação do peptídeo tipo glucagon 1 (GLP-I) ou do peptídeo insulinotrópico dependente de glicose (GIP) aos seus receptores nas células $\beta$ pancreáticas desencadeiam uma série de reações que culminam no aumento do

\subsubsection{CART (TRANSCRITO REGULADO POR COCAÍNA E ANFETAMINA)}

CART foi primeiro descoberto como o produto de um mRNA cuja a expressão é regulada pela administração aguda de cocaína e anfetaminas. Embora pouco se saiba sobre o seu metabolismo, CART é processado em dois peptideos biologicamente ativos, o 42-89 e o 49-89. CART é implicado em uma variedade de processos fisiológicos, incluindo a ingestão alimentar, remodelação óssea, processamento sensorial, estresse e ansiedade, regulação endócrina e propriedades de psicoestimulantes.

Alguns estudos mostram a importância fisiológica da CART no controle da alimentação e dependência a psicoestimulantes como cocaína e anfetaminas. Polimorfismos do gene CART afetam vários pontos da alimentação e os níveis de seu mRNA estão aumentados no cérebro vítimas de overdose de cocaína. 


\subsection{O EFEITO DAS INCRETINAS NA FISIOLOGIA NORMAL}

A existência de incretinas foi sugerida pelo fato de que os níveis de insulina são duas a três vezes mais altos após a ingestão oral de glicose do que pela administração da mesma quantidade de glicose por via intravenosa. Essas diferenças podem ser atribuídas à secreção pós-prandial de GIP e GLP-1 e sua ação sobre o balanço de insulina e glucagon.

A homeostase da glicose em jejum é estreitamente regulada pela interação da insulina com o glucagon que, posteriormente, controlam a liberação de glicose hepática, bem como a captação de glicose periférica. Além disso, sinais neurais ou autonômicos, bem como outros fatores metabólicos (aminoácidos e ácidos graxos livres), parácrinos (somatostatina) e endócrinos têm grande influxo sobre a secreção de insulina e o glucagon.

No estado pós-prandial, este equilíbrio é alterado significativamente e outros fatores derivados do intestino tornam-se cada vez mais relevantes. Assim, o primeiro mecanismo através do qual o intestino influencia a glicemia pós-prandial é a velocidade do esvaziamento gástrico. Uma diminuição da taxa de esvaziamento gástrico é aceita como uma estratégia terapêutica para diminuir o aumento da glicose pós-prandial em diabéticos, enquanto o aumento da velocidade de esvaziamento gástrico pode aumentar a glicemia, induzido pela alimentação. Estudos em voluntários humanos estimam que cerca de $35 \%$ da variação da glicemia pós-prandial podem ser atribuídos às diferenças no esvaziamento gástrico. É claro que variações na absorção de nutrientes também influenciarão a glicemia pós-prandial.

Além do esvaziamento gástrico, o controle da glicemia pelo intestino pode ser feito pelos peptídeos GLP-1 e GIP por meio de suas influências sobre a secreção de insulina ou de glucagon. Em conjunto, a ação insulinotrópica desses hormônios é capaz de mediar cerca de $65 \%$ da resposta de insulina após alimentação em pacientes com DMT2.

Os níveis plasmáticos de GIP e GLP-1 começam a subir 10-15 min após a ingestão de uma refeição, alcançam picos de 150-300 pmol/L e 25-40 pmol/L, respectivamente, para retornar aos níveis basais após $180 \mathrm{~min}$. Tanto GIP como GLP1 aumentam a secreção de insulina induzida pela glicose, sendo o GIP o de maior importância em condições fisiológicas. Além disso, o GLP-1 diminui a secreção de glucagon e a motilidade gástrica, enquanto o GIP aumenta moderadamente os níveis de glucagon e não tem efeitos sobre o esvaziamento gástrico. 


\subsection{SINAIS HORMONAIS RELACIONADOS À ADIPOSIDADE}

Além dos hormônios intestinais, alguns sinais vindos ou não do tecido adiposo, estão envolvidos na regulação do balanço energético e da adiposidade a longo prazo.

Os níveis circulantes de insulina são proporcionais ao tecido adiposo e estão envolvidos na regulação, em longo prazo, do balanço energético. A insulina é rapidamente secretada após uma refeição e atravessa a barreira hematoencefálica de forma dose-dependente, por mecanismo de saturação de receptor. Ela atua no núcleo arqueado hipotalâmico, onde os receptores de insulina são altamente expressos, via ativação dos neurônios POMC.

Outro sinal de adiposidade, a leptina, é produzida e secretada principalmente pelos adipócitos. Essa adipocina mantém um controle em longo prazo da adiposidade e regula mudanças metabólicas adaptativas em resposta a modificações nutricionais.

A leptina é transportada pela barreira hematoencefálica e exerce seus efeitos anorexígenos por meio do núcleo arqueado do hipotálamo, onde tanto os neurônios NPY/AgRP quanto os POMC/CART expressam receptores de leptina. Assim, a leptina inibe os neurônios NPY/AgRP e ativa os POMC/CART resultando em redução da ingestão alimentar e aumento do gasto energético. Já os baixos níveis de leptina ativam vias anabólicas e inibem vias catabólicas, aumentando neurônios NPY/AgRP e bloqueando a atividade dos neurônios POMC/CART, o que resulta em aumento do tamanho da refeição e diminuição do gasto energético.

A Tabela 16.1 mostra as principais características dos hormônio ligados à regulação da ingestão alimentar. 


\begin{tabular}{|c|c|c|c|}
\hline HORMÔNIO & SIITIO DE SÍNTESE & $\begin{array}{l}\text { FATORES QUE ESTIMULAM (+) } \\
\text { OU INIBEM (-) A SECREÇÃO }\end{array}$ & $\begin{array}{l}\text { PAPEL NA HOMEOSTASE ENERGÉTICA } \\
\text { E GLICÊMICA }\end{array}$ \\
\hline Grelina & $\begin{array}{l}\text { Células tipo X/A da } \\
\text { mucosa gástrica }\end{array}$ & $\begin{array}{l}\text { + falta de sono, restrição calórica } \\
\text { - macronutrientes, cirurgia bariátrica }\end{array}$ & $\begin{array}{l}\text { Iniciador da refeição } \\
\text { Regulador do peso corporal } \\
\text { Possivel papel patogênico na obesidade }\end{array}$ \\
\hline NPY & $\begin{array}{l}\text { Núcleo arqueado do } \\
\text { hipotálamo }\end{array}$ & $\begin{array}{l}\text { + baixa leptina, hipoglicemia, balanço } \\
\text { energético, hipoinsulinemia }\end{array}$ & $\begin{array}{l}\text { Inibidor da termogênese } \\
\uparrow \text { a ingestão alimentar } \\
\text { Promove a adipogênese }\end{array}$ \\
\hline AgRP & $\begin{array}{l}\text { Núcleo arqueado do } \\
\text { hipotálamo }\end{array}$ & $\begin{array}{l}\text { + ausência leptina , balanço energético negativo } \\
\text { - infusão de leptina }\end{array}$ & $\begin{array}{l}\uparrow \text { a ingestão alimentar } \\
\text { Potencial terapeutico (anorexia, obesidade) } \\
\text { Possivel papel patogênico na obesidade }\end{array}$ \\
\hline GLP-1 & Células $L$ intestinais & $\begin{array}{l}\text { + cirurgia bariátrica, macronutrientes } \\
\text { - somatostatina, restrição calórica }\end{array}$ & $\begin{array}{l}\uparrow \text { a saciedade e saciação } \\
\uparrow \text { secreção insulina induzida por glicose } \\
\text { Possivel papel patogênico na obesidade }\end{array}$ \\
\hline OXM & Células $L$ intestinais & + macronutrientes & $\begin{array}{l}\uparrow \text { a saciedade e saciação } \\
\uparrow \text { gasto energético }\end{array}$ \\
\hline PYY & Células $L$ intestinais & $\begin{array}{l}\text { + cirurgia bariátrica, macronutrientes, atividade } \\
\text { física. }\end{array}$ & $\begin{array}{l}\uparrow \text { a saciedade e saciação } \\
\uparrow \text { gasto energético } \\
\text { Regulação do peso corporal } \\
\text { Possivel papel patogênico na obesidade }\end{array}$ \\
\hline PP & $\begin{array}{l}\text { Células } F \text { das ilhotas } \\
\text { pancreáticas }\end{array}$ & $\begin{array}{l}\text { + distensão gástrica e macronutrientes, } \\
\text { atividade física, CCK, gastrina } \\
\text { - somastotastina }\end{array}$ & $\begin{array}{l}\uparrow \text { a saciedade e saciação } \\
\uparrow \text { o gasto energético } \\
\text { Possível papel patogênico na obesidade }\end{array}$ \\
\hline CCK & Células I duodeno e íleo & $\begin{array}{l}\text { + refeições ricas em gorduras e proteinas } \\
\text { - ácidos biliares }\end{array}$ & $\begin{array}{l}\uparrow \text { a saciação } \\
\text { Possível papel patogênico na obesidade }\end{array}$ \\
\hline
\end{tabular}

Tabela 16.1 - Resumo das características e ação dos hormônios intestinais e de alguns sinais de adiposidade importantes

\subsection{HORMÔNIOS INTESTINAIS NA DOENC̣A}

\subsubsection{OBESIDADE}

A obesidade é definida como um acúmulo anormal ou excessivo de gordura, representando um risco para a saúde. Tal doença representa o principal fator de risco para um grande número de doenças crônicas, tais como o Diabetes Mellitus do tipo 2 (DMT2) e doenças cardiovasculares. A obesidade tornou-se importante problema de saúde em todo o mundo, sendo que sua prevalência aumenta rapidamente. A Organização Mundial da Saúde estima que, em 2015, aproximadamente 2,3 bilhões de adultos em todo o mundo estarão com excesso de peso, e mais de 700 milhões estão obesos.

A obesidade decorre de um estado no qual a ingestão excede o gasto energético durante um prolongado período. Além dos fatores fisiológicos que regulam a ingestão alimentar e o gasto energético, outros fatores como os psicológicos e emocionais podem conduzir ao excesso na ingestão além de suas reais necessidades. 
Além das terapias tradicionais propostas para a prevenção e tratamento da obesidade, outras medidas são propostas com base no conhecimento dos mecanismos de ação de hormônios intestinais. Os hormônios intestinais envolvidos na regulação do apetite são um alvo atraente para o desenvolvimento de drogas que visam a causar perda de peso eficaz com o mínimo de efeitos colaterais.

Dentre os hormônios de interesse estão a amilina, que apresenta níveis mais elevados em indivíduos obesos do que em magros. Estudos experimentais mostram que sua administração é capaz de retardar o esvaziamento gástrico, reduzir a ingestão alimentar e o peso corporal.

Alguns estudos mostram que os níveis circulantes de PP são significativamente menores em obesos, quando comparados aos eutróficos. Em camundongos, a administração periférica aguda ou crônica de PP reduziu a ingestão alimentar. Esse efeito é ainda mantido em camundongos deficientes em leptina (ob/ob), nos quais injeções intraperitoneais de PP reduziram o ganho de peso corporal. Além disso, camundongos que superexpressam PP são magros e apresentam redução na ingestão alimentar. Esses resultados são confirmados em estudos com indivíduos eutróficos, nos quais a infusão intravenosa de PP resultou em redução de $25 \%$ na ingestão alimentar por 24 horas e reduziu a velocidade de esvaziamento gástrico. Pacientes com síndrome de Prader-Willi, caracterizada por hiperfagia e obesidade extrema, apresentam níveis circulantes reduzidos de PP. A administração intravenosa desse peptídeo foi capaz de reduzir a ingestão alimentar nesses pacientes, sugerindo que a deficiência de PP contribui em parte para a hiperfagia observada nessa síndrome. Embora o PP represente um potencial alvo na pesquisa de drogas anti-obesidade, esse é rapidamente degradado na circulação, o que limita seu uso clínico. O desenvolvimento de análogos com ação mais duradoura pode representar uma possível opção no tratamento para a obesidade.

CCK reduz a ingestão alimentar em roedores e humanos. Entretanto, apesar de estudos com infusão de CCK em ratos no início de cada refeição tenha reduzido a ingestão, tal efeito foi compensado por um aumento na frequência das refeições, mantendo o aporte calórico semelhante. Em outros trabalhos, utilizando infusão intraperitoneal contínua de CCK não foi capaz de suprimir a ingestão de alimentos.

A administração periférica de PYY em indivíduos eutróficos e obesos também foi capaz de reduzir a ingestão alimentar. Adicionalmente ao efeito anorexígeno do PYY, estudos experimentais mostraram que esse peptídeo aumenta o gasto energético e retarda o esvaziamento gástrico. Além de contribuir para a saciedade pós-prandial, foi demonstrado que o PYY reduz a motivação para buscar alimentos com alto teor de gorduras, sugerindo que tal peptídeo pode ajudar a prevenir a ingestão reincidente de dietas hiperlipídicas. 
Em obesos, os níveis circulantes de PYY são baixos, contudo, tais pessoas permanecem sensíveis aos efeitos anorexígenos da infusão venosa de PYY, sugerindo ocorrer uma deficiência relativa na sua concentração em obesos, mas a sensibilidade à sua ação está preservada. Esses achados alimentam o interesse no PYY como um importante sinal de saciedade e um mediador da homeostase energética, sendo assim outra possível terapia para a obesidade.

A administração de OXM reduz a ingestão alimentar e aumenta o gasto energético em estudos clínicos e experimentais. Indivíduos com sobrepeso ou obesidade que receberam injeção periférica de OXM 30 minutos antes de uma refeição apresentaram redução de mais de $25 \%$ no consumo de energia, induzindo à redução de cerca de $2 \mathrm{~kg}$ no peso corporal comparado ao controle, sugerindo seu potencial uso no tratamento da obesidade. A principal limitação do seu uso é que a OXM à semelhança do GLP-1, é inativada pela DPP-IV. Assim, análogos da OXM resistentes à degradação pela DPP-IV estão sendo desenvolvidos para viabilizar seu uso no tratamento da obesidade.

A infusão intravenosa de GLP-1 em indivíduos eutróficos ou obesos resulta no retardo do esvaziamento gástrico e na redução na ingestão alimentar de forma dose-dependente. Embora vários experimentos mostrem que GLP-2 não apresenta efeitos na ingestão alimentar, alguns estudos revelam uma ação de GLP-2 em retardar o esvaziamento gástrico, embora em menor intensidade do que o GLP-1.

É sabido que um excesso de glicocorticoide é associado com a obesidade, especialmente com a obesidade abdominal. Vários trabalhos indicam que o efeito dos glicocorticoides sob o CART pode ser direto, uma vez que corticosterona aumenta os níveis de CART. Os níveis de CART no sangue apresentam um ritmo circadiano semelhante ao dos glicocorticoides e alterado pela adrenalectomia. Estes resultados sugerem que CART desempenha um papel na função na atividade do eixo hipotálamo-pituitário-adrenal, que pode ser relevante para a sua ação na ingestão alimentar.

CART e obesidade humana: o papel de CART na obesidade pode ser inferido pela localização de seu gene no cromossomo 5q13-14, um locus conhecido de susceptibilidade à obesidade humana. Polimorfismos do gene CART, assim como diferenças nos níveis de peptídeo CART, são implicados na obesidade hereditária, nas variações no gasto energético, no comportamento de ingestão alimentar e na anorexia nervosa. Algumas das provas mais convincentes de que CART desempenha um papel importante na obesidade humana vem do estudo em uma família italiana de obesos. Uma mutação no gene CART resultou na substituição de uma leucina por fenilalanina, o que levou ao quadro precoce de obesidade grave ao longo das três generações que mantiveram a mutação. Vários polimorfismos de CART estão sendo agora descritos e associados com a ingestão alimentar e obesidade. 


\subsubsection{CIRURGIAS BARIÁTRICA E METABÓLICA PARA O CONTROLE DO DMT2}

O papel dos hormônios intestinais nos resultados favoráveis da cirurgia bariátrica é alvo de estudos diversos. A cirurgia bariátrica é o tratamento mais eficaz para a perda de peso naqueles com obesidade extrema, levando à melhora das comorbidades e à redução da mortalidade. Essa cirurgia é realizada com o objetivo de restringir o aporte energético ou a absorcão dos nutrientes pela modificação da anatomia do trato gastrointestinal. Após a cirurgia, muitos pacientes obesos mantêm uma ingestão calórica muito baixa sem a sensação de fome excessiva. Estes eventos podem estar relacionados com as alterações nos hormônios intestinais decorrentes dos procedimentos cirúrgicos.

Os procedimentos de cirurgia bariátrica são classificados como restritivos, disabsortivos ou combinados (restritivo e disabsortivo). Os procedimentos puramente restritivos, como gastroplastia e bandagem gástrica, têm como objetivo apenas a redução da ingestão alimentar pela restrição do volume gástrico; este passa de 700 $\mathrm{mL}$ em um indivíduo normal para $50 \mathrm{~mL}$ naquele submetido ao procedimento.

$\mathrm{O}$ procedimento misto é representado pelo bypass gástrico em Y de Roux (RYGB). Neste procedimento, ocorre também a restrição pela bandagem gástrica associada à secção do jejuno distal. Após a secção do jejuno, sua extremidade distal é ligada ao reservatório gástrico (ramo de Roux ou alimentar) e o lado proximal (duodeno e jejuno proximal) chamado de ramo biliopancreático é ligado no íleo. Assim, os alimentos ingeridos passam pelo ramo alimentar, mas sem ter contato com as enzimas para sua digestão que estão no ramo biliopancreático. Por outro lado, o ramo biliopancreático contém as secreções necessárias para a digestão e grande parte da superfície absortiva, mas não recebe o alimento. Apenas após a ligação do ramo biliopancreático no íleo terminal (chamado de ramo comum), alimentos e enzimas entram finalmente em contato.

Os procedimentos disabsortivos usam técnicas semelhantes às utilizadas no procedimento misto, mas o ramo comum é bem menor. Um exemplo é o bypass biliopancreático, que consiste de uma pequena restrição gástrica associada a um longo ramo biliopancreático, deixando o ramo comum com apenas $50-75 \mathrm{~cm}$.

Além da restrição física da ingestão e absorção de nutrientes, modificações no perfil de secreção de hormônios intestinais contribuem para que o sucesso da cirurgia bariátrica. Os procedimentos restritivos levam à redução da produção de grelina, contribuindo para a redução no apetite e no peso corporal. Alguns estudos encontraram também aumento de PYY circulante após a cirurgia, sugerindo sua participação na redução da ingestão alimentar e a perda de peso. Outros 
estudos relatam ainda o aumento na secreção de OXM e GLP-1, importantes na redução da ingestão alimentar e no aumento da secreção de insulina.

Desse modo, um crescente de evidências aponta para o papel dos hormônios intestinais e suas alterações para a obtenção do sucesso do tratamento, entretanto, como a cirurgia bariátrica não é isenta de riscos e pesquisas têm sido realizadas para se obter esses mesmos efeitos no perfil de hormônios intestinais através de agentes farmacologicos.

Mais intrigantes são os benefícios da cirurgia no DMT2, uma complicação comum da obesidade. Certamente a redução de peso melhora o diabetes, mas frequentemente o DM é revertido antes que ocorra perda de peso significativa.

Duas hipóteses principais foram propostas para explicar esses efeitos da cirurgia metabólica em diabetes, independentemente da perda de peso. São as hipóteses do "hindgut" (ou intestino distal) e do "foregut" (intestino proximal). A hipótese do "hindgut" sugere que a melhora do DMT2 é decorre da liberação mais rápida dos nutrientes para o intestino delgado distal, aumentando a liberação de incretinas como o GLP-1 e GIP que, por sua vez, aumentam a liberação de insulina, melhorando do metabolismo da glicose. De fato, o aumento do GLP-1 no plasma estimula a secreção de insulina e suprime a secreção de glucagon, aumentando assim a captação da glicose.

Por outro lado, a hipótese "foregut" sugere que a exclusão do intestino delgado proximal (como ocorre no "bypass” gástrico) reduz ou suprime a secreção de hormônios anti-incretinas que antagonizam os efeitos da incretinas, com a consequente melhora no controle glicêmico. $\mathrm{O}$ efeito do bypass gástrico é também visto no metabolismo hepático, melhorando a sensibilidade à insulina deste órgão. Este fato ocorre, provavelmente, pela redução da gliconeogênese hepátia, sem afetar a sensibilidade periférica à insulina.

Curiosamente, embora o "bypass” gástrico e a derivação biliopancreática melhorem a sensibilidade à insulina os mecanismos parecem ser diferentes: com a derivação biliopancreática, a melhor sensibilidade à insulina, está ligada à menor excreçào deste hormônio, enquanto no bypass gástrico, esta melhora ocorre consequente à maior secreção de insulina.

\subsubsection{DIABETES MELLITUS TIPO 2 (DMT2)}

O Diabetes Mellitus é reconhecido como um grupo heterogêneo de desordens onde os elementos comuns são a hiperglicemia e a intolerância à glicose, decorrentes da deficiência ou da ação prejudicada da insulina. O Diabetes Mellitus do tipo 2 (DMT2) é frequentemente associado à obesidade, em virtude da resistência à insulina imposta pelo excesso de peso. 
O DMT2 é uma epidemia global com prevalência mundial atual estimada em 6,6\% (285 milhões de pessoas), com previsão de aumento para 7,8\% (438 milhões de pessoas) em 2030. As influências negativas à saúde, sociais e econômicas são enormes e, consequentemente, o DMT2 representa um grande desafio para os sistemas de saúde de todo o mundo.

Com base no entendimento atual da fisiopatologia do DMT2, múltiplas intervenções são propostas com o objetivo de melhorar o controle glicêmico e retardar a progressão da doença. As terapias baseadas no uso de incretinas representam nova classe de medicamentos para o tratamento de DMT2, e podem evitar alguns dos efeitos colaterais dos tratamentos convencionais (hipoglicemia, ganho de peso, problemas gastrointestinais e edema periférico), efeitos esses que dificultam o controle glicêmico adequado nestes pacientes.

As vantagens das incretinas OXM e GLP-1 descritas para a obesidade também são válidas para o DMT2. OXM e GLP-1 têm não só efeitos de incretina, mas também efeitos tróficos, aumentando a massa de células $\beta$ pancreáticas. O GLP-1 também inibe a secreção de glucagon dependente de glicose, melhorando a sensibilidade à insulina. Ambas são inativadas pela enzima DPP-IV. Assim, grande é a busca por inibidores da DPP-IV ou de análogos de OXM ou GLP-1 resistentes à sua ação para o tratamento do DMT2. Secretagogos de GLP-1, particularmente alguns tipos de agonistas, também se tornaram alvos importantes para o desenvolvimento de novas drogas para o tratamento de DMT2.

Alguns hormônios intestinais e a leptina, embora não sejam classificados como incretinas, desempenham importante papel no controle da glicemia. A amilina, por exemplo, exerce efeitos glicorregulatórios que complementam a ação da insulina, suprimindo a secreção de glucagon pós-prandial. A administração de amilina melhora o controle glicêmico e leva à perda de peso em pacientes com DMT2.

A administração periférica de PYY ou o agonista de seu receptor Y2 melhora a sensibilidade à insulina mesmo em doses que não afetam o peso corporal.

A grelina é um hormônio por demais intrigante nos pacientes diabéticos, pois além de participar ativamente na modulação da ingestão alimentar e motilidade gastrointestinal tem um comportamento "bifásico em DMT2". Seus níveis estão elevados na fase precoce do DM, o que se correlaciona com a alimentação hiperfágica e motilidade gastrointestinal acelerada. Em contraste, os níveis de grelina no plasma podem estar diminuídos nos últimos estágios do DM. Este fato está relacionado com falta de apetite, perda de peso e gastroparesia comum desta fase. 


\subsubsection{COMPULSÃO ALIMENTAR E DEPENDÊNCIA DE DROGAS: O PAPEL DO CART}

A maioria dos estudos suporta a hipótese de que a CART é um importante regulador do apetite e também da dependência à psicoestimulantes. Anatomicamente peptídeos e/ou mRNA do CART são encontrados em diversas regiões, associadas com a alimentação e reforço/recompensa (ligadas à dependencia de drogas). Há ainda forte associação anatômica entre CART e outros sistemas associados à alimentação e às propriedades gratificantes de psicoestimulantes. CART tem sido associado à leptina e glicocorticoides, dois importantes reguladores da alimentação, bem como ao GABA, envolvido no efeito de recompensa produzida por psicoestimulantes. Além disso, várias linhas de evidências farmacológicas e comportamentais sugerem que os peptídeos CART modulam o sistema dopaminérgico. Em virtude da associação de CART com o sistema dopaminérgico mesolímbico talvez CART possa ter implicações em outros distúrbios neurológicos que envolvem a transmissão dopaminérgica. Na verdade, a obesidade e o abuso de drogas são altamente prevalentes entre os pacientes que sofrem de transtornos mentais, como a esquizofrenia.

Por isso há um grande potencial do uso de CART como alvo terapêutico para o tratamento de transtornos alimentares humanos, incluindo a obesidade e a anorexia nervosa, assim como para otratamento da dependência de psicoestimulantes.

\subsection{INTERAC̣ÃO DOS HORMÔNIOS INTESTINAIS}

Grande parte dos estudos tem como objetivo isolar os hormônios intestinais e analisar seus efeitos individuais na ingestão alimentar e no gasto energético. Entretanto, quando uma refeição é consumida, ocorrem múltiplas alterações na secreção de hormônios intestinais, os quais podem exercer efeitos no apetite, em sinergismo, adição ou antagonismo com os demais hormônios intestinais. Certas combinações, como, por exemplo, PYY + GLP-1 ou amilina, possuem efeitos aditivos na inibição da ingestão alimentar, enquanto outras combinações, por exemplo, o PYY + PP, não parecem ter qualquer efeito aditivo sobre ingestão alimentar.

Mais investigações são necessárias, a fim de se descobrir combinações sinérgicas dos hormônios intestinais, de modo a desenvolver um tratamento eficaz contra a obesidade, com a redução da ingestão alimentar e aumento do gasto energético, e contra o DMT2, principal transtorno metabólico associado à obesidade. 


\section{REFERÊNCIAS BIBLIOGÁFICAS}

CEGLA, J.; TAN, T. M.; BLOOM, S. R. Gut-brain cross-talk in appetite regulation. Current Opinion in Clinical Nutrition and Metabolic Care. 13(5): 588-593, 2010.

SUZUKI, K.; SIMPSON, K. A.; MINNION, J. S.; SHILLITO, J. C.; BLOOM, S. $\mathrm{R}$. The role of gut hormones and the hypothalamus in appetite regulation. Endocrine Journal. 57(5): 359-372, 2010.

TAHRANI, A. A.; PIYA, M. K.; KENNEDY, A.; BARNETT, A. H. Glycaemic control in type 2 diabetes: Targets and new therapies. Pharmacology \& Therapeutics. 125(2): 328-361, 2010.

NEARY, M. T.; BATTERHAM, R. L. Gut hormones: Implications for the treatment of obesity. Pharmacology \& Therapeutics. 124(1): 44-56, 2009.

VALASSI, E.; SCACCHI, M.; CAVAGNINI, F. Neuroendocrine control of food intake. Nutrition, Metabolism \& Cardiovascular Diseases.18(2): 158-168, 2008.

HAMEED, S.; DHILLO, W. S.; BLOOM, S. R. Gut hormones and appetite control. Oral Diseases. 15(1): 18-26, 2009.

FREEMAN, J. S. The pathophysiologic role of incretins. The Journal of the American Osteopathic Association. 107(3): S6-S9, 2007.

WHO - WORLD HEALTH ORGANIZATION. Obesity and overweight. Disponível em: < http://www.who.int/mediacentre/factsheets/fs311/en/>. Acesso em: 20 set. 2010.

KARRA, E.; BATTERHAM, R. L. The role of gut hormones in the regulation of body weight and energy homeostasis. Molecular and Cellular Endocrinology. 316(2): 120-128, 2010.

IDF - INTERNATIONAL DIABETES FEDERATION. Diabetes and impaired glucose tolerance. Disponível em: < http://www.diabetesatlas.org/content/ diabetes-and-impaired-glucose-tolerance>. Acesso em: 29 set. 2010. 
